\title{
The Africa Regional SGBV Network Learning Brief Series: Learning updates from Uganda (Brief \#7)
}

Population Council

Follow this and additional works at: https://knowledgecommons.popcouncil.org/departments_sbsr-rh

Part of the Demography, Population, and Ecology Commons, Domestic and Intimate Partner Violence Commons, Family, Life Course, and Society Commons, and the International Public Health Commons How does access to this work benefit you? Let us know!

\section{Recommended Citation}

"The Africa Regional SGBV Network Learning Brief Series: Learning updates from Uganda (Brief \#7)." Nairobi: Population Council, 2016. 
Population Council

The Africa Regional SGBV Network Learning Brief Series

Fostering a Multisectoral Response to SGBV in Humanitarian Settings

\section{Learning Updates from Uganda (Brief \#7)}

Sexual and gender-based violence (SGBV) in humanitarian contexts is recognized by the UN Refugee Agency (UNHCR) as a global concern and as a priority in its programming. Crisis-affected populations often face multiple forms of SGBV at multiple time periods (during conflict, during flight from conflict, and within post-conflict settings). The Africa Regional SGBV Network, set up in 2006, is addressing SGBV in humanitarian contexts in East and Southern Africa. This Learning Brief is one in a series of two that share critical findings on effective responses to the issue in Uganda.

\section{Testing a Community-Based SGBV Prevention Model in Humanitarian Settings in Uganda}

Although SGBV is recognized as a growing problem in humanitarian settings, and the highest number of forcibly displaced people in recorded history was reported by UNHCR in 2015, there are still not many evaluations of primary SGBV prevention models in these contexts.

Under the Africa Regional SGBV Network, the Population Council and Lutheran World Federation (LWF) collaborated with a range of partners (including the Uganda Refugees Department (Office of the Prime Minister), the Child Health and Development Centre, Thohoyandou Victim Empowerment Programme (TVEP), and UNHCR) to assess the effectiveness of

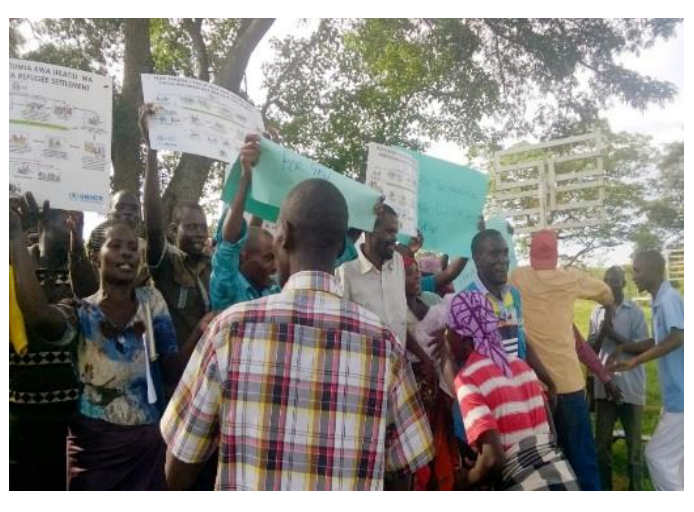
implementing a community-based SGBV prevention model in humanitarian settings. Referred to as the 'Zero Tolerance Village Alliance' intervention, the model was pioneered by TVEP and first implemented in rural South Africa. The Africa Regional SGBV Network introduced and assessed the model in Rwamwanja Refugee Settlement in Kamwenge District, Western Uganda. 
The 'Zero Tolerance Village Alliance' intervention involves a range of intensive community mobilization activities to change SGBV norms, including dialogues with, and training of, a critical mass of community members. Communities drive the process by establishing a stakeholders' forum tasked with ensuring that critical community mobilization activities occur, and with signing a Memorandum of Agreement to formalize the process. Communities meeting a series of agreed-upon criteria over time, showing their commitment to eradicating SGBV, are formally inducted into an alliance of like-minded communities. This induction involves public pledge-taking by men against SGBV perpetration.

\section{What we learned in the beginning}

At baseline, we learned a lot that helped guide the adaptation of the intervention for a humanitarian setting. These findings are applicable to many other humanitarian contexts in the region:

1. In Rwamwanja Refugee Settlement, literacy levels are low among the overall population, but women were at least twice as likely as men to have never been to school. Many SGBV interventions involve the use of bill boards, posters, leaflets, and other materials, which cannot be accessed by people with low literacy levels.

Recommendation: Ensure that SGBV interventions in humanitarian settings include non-literacy-based messaging in order to reach community members with little formal education.

2. Although they were much more likely to be survivors of SGBV, women were significantly less likely than men to be aware of campaigns to end such violence.

Recommendation: Develop and implement targeted approaches for reaching women with SGBV information and campaigns, taking literacy levels and the cultural context into consideration.

3. Rape-related pregnancy emerged as a key concern in this setting.

\section{Recommendations:}

- Develop messages to de-stigmatize early reporting of rape directly to SGBV clinics, or to health facilities in the absence of specialized clinics

- Messages must include information on where the services are available and hours of operation 
- Post-rape care must be strengthened so that pregnancy prevention services are available at health facilities

- Psychological support services must be strengthened to ensure providers are equipped to address both the psychological and reproductive health needs of survivors presenting with raperelated pregnancy

4. Findings suggest that non-partner sexual violence was more likely to be experienced at home by women. The Ugandan policy of providing 1.25 acres of land per household is important for refugees. However, it potentially leads to increased vulnerability of women, given that homes are distantly-located from one another.

Recommendation: Re-configure residential arrangements for female-headed households in Ugandan humanitarian settings to ensure enhanced security. For instance, female household heads could reside together on a common piece of land, and still have land available for farming.

5. Care-seeking for sexual Intimate Partner Violence (IPV) was low.

Recommendation: Develop and disseminate appropriate IEC messages to publicize the availability of IPV care. These must incorporate issues such as the importance of IPV care (even when injuries do not seem to be severe) and deal with issues of shame, as these barriers were reasons for low care-seeking behaviour among survivors. Building capacity to respond to IPV as a component of post-rape care would also be important.

\section{What we learned at the end}

The endline evaluation measured the effectiveness of the 'Zero Tolerance Village Alliance' model in a humanitarian setting, and showed that, overall, the model is an effective means of fostering SGBV prevention:

\section{Effectiveness of the Zero Tolerance Village Alliance}

The model proved to be particularly effective in:

- moderating negative gender attitudes and beliefs related to SGBV

- positively changing perceptions of community SGBV norms

- reducing the occurrence of:

o physical intimate partner violence (IPV) (for men and women) 

o sexual IPV (for men)
o non-partner physical violence (for men and women)
○ non-partner sexual violence (for women)

- improving understanding of what rape is as well as its consequences for women, girls, and the community

- increasing awareness of existing SGBV interventions

The 'Zero Tolerance Village Alliance' intervention was less effective in:

- changing negative male attitudes toward women's sexual autonomy in intimate partnerships

- reducing the occurrence of sexual IPV for women

For a more detailed report:

http://www.popcouncil.org/uploads/pdfs/2016RH_SGBVPreventionUgandaZTVA.pdf

Since 2006, the Africa Regional SGBV Network has worked to build effective responses to SGBV in low-resource settings, focusing on those who have experienced violence, as well as on violence prevention. From 2014-2017, the network is addressing the needs of two vulnerable populations - children and refugees.

(C) 2016 The Population Council, Inc.

Network Contact:

Population Council

General Accident Insurance House

Ralph Bunche Road

Nairobi, Kenya

$\mathrm{T}:$ + 254202713480

E: info.nairobi@popcouncil.org
LWF Contact:

Plot 1401 Gaba Road, Nsambya

P.O Box 5827

Kampala, Uganda

T: +256 264006/7/8

E: paul.orik@lwf.or.ug,

prosmollya@yahoo.com
TVEP Contact:

2 Old Embassy Building

Sibasa

Thohoyandou 0970

South Africa

E: fiona@tvep.org.za

We gratefully acknowledge the support of the Regional Team for Sexual and Reproductive Health and Rights, Embassy of Sweden, Lusaka, Zambia.
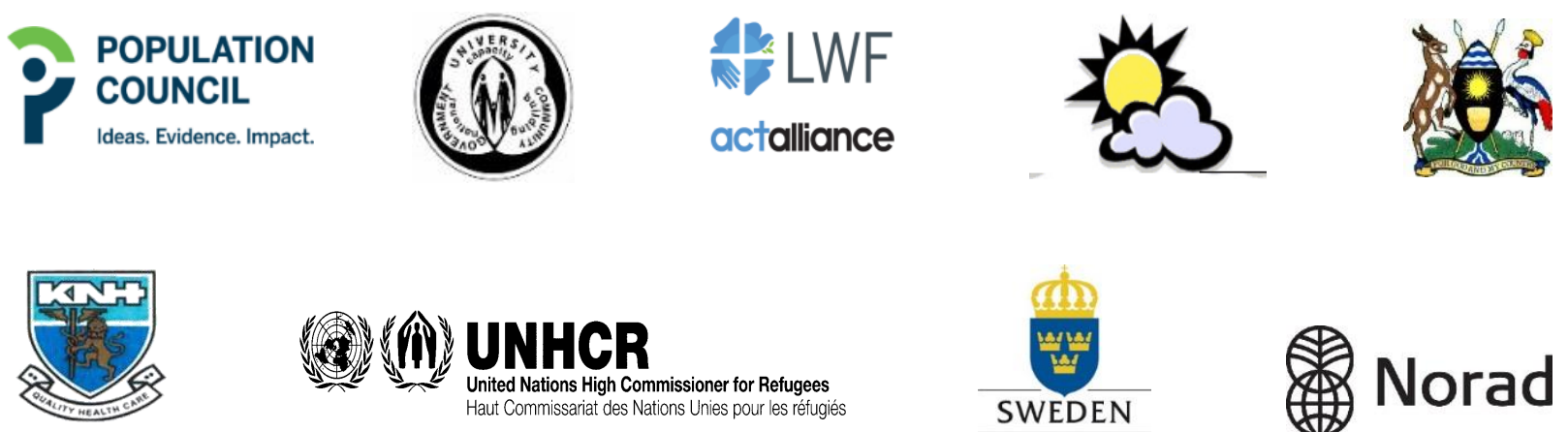